\section{Entrevista: Yves Schwartz}

Interview: Yves Schwartz
Resumo Yves Schwartz é membro do Instituto Universitário da França (IUF) e diretor científico do Departamento de Ergologia da Université de Provence. Entre seus trabalhos, destacamos Expérience et connaissance du travail (Méssidor: Eds. Sociales, 1988), Travail et philosophie: convocations mutuelles (Tolouse, Octarès, 1992) e Le paradigme ergologique ou um métier de philosophe (Tolouse, Octarès, 2000). Desde os anos 90, desenvolve cooperação com grupos de pesquisa na Fiocruz (Pós-graduação em Saúde Pública, subárea Saúde, Trabalho e Ambiente), na Uerj (Pós-graduação em Psicologia Social, em Letras e na Faculdade de Engenharia), na UFF (Pós-graduação em Engenharia de Produção e em Psicologia), na Unirio, na UFRJ (Pós-graduação em Engenharia de Produção) e na UFRRJ. Esta entrevista foi realizada em outubro de 2005. Nela, Yves Schwartz discute alguns dos principais conceitos da perspectiva ergológica, além de apontar aspectos históricos e teórico-metodológicos relacionados à emergência desta perspectiva na França dos anos 80. A perspectiva ergológica desenvolvida através do "dispositivo dinâmico de três pólos", associa, de forma original, profissionais de pesquisa a trabalhadores na investigação do "mundo do trabalho" e suas transformações. Entre outras influências, destaca a colaboração com o grupo de pesquisa-intervenção de Ivar Oddone e a influência da obra de Georges Canguilhem ${ }^{1}$.
Abstract Yves Schwartz, member of the France University Institute (IUF) and scientific director of the Department of Ergology of the Université de Provence. Among his works we point out Expérience et connaissance du travail (Méssidor/ Eds. Sociales, 1988), Travail et philosophie: convocations mutuelles (Tolouse, Octarès, 1992) e Le paradigme ergologique ou um métier de philosophe (Tolouse, Octarès, 2000). Since the 1990's, he develops a cooperation with research groups at Fiocruz (Post-graduate in Public Health, subarea Health, Work and Environment), at UERJ (Post-graduate in Social Psychology, in Literature \& Languages and College of Engineering), at UFF (Post-graduate in Production Engineering and Psychology), at Unirio, at UFRJ (Post-graduate in Production Engineering) and at UFRRJ. This interview was held on October 2005. In it, Yves Schwartz discusses some of the main concepts of the ergological perspective, in addition to pointing out historical and theoretical-methodological aspects related to the emergency of this perspective in France in the 80's. The ergological perspective developed through the "three-pole dynamic device", associates, on an original manner, research professionals to workers in the investigation of the "world of work" and its transformations. Among other influences, he highlights the collaboration with the research-intervention group of Ivar Oddone and the influence of the work of Georges Canguilhem. 


\section{Revista}

Poderia nos falar sobre o contexto histórico, socioeconômico, político e acadêmico de surgimento da perspectiva ergológica?

\section{Yves Schwartz}

$\mathrm{Na}$ verdade, são muitos contextos. Em particular, o contexto socioeconômico das mudanças do trabalho nos anos 80, na Europa. Um período descrito como de declínio do taylorismo, do surgimento das novas técnicas e tecnologias, assim como de redução do tamanho das empresas e fábricas. Um contexto de mudança - do trabalho e da sociedade. Na universidade, como professores, como pesquisadores, entendemos que deveríamos integrar essas mudanças ao nosso ofício, propondo cursos e pesquisas afinados com essas mudanças. A nossa questão, para ser breve, era: "é verdade que muitas coisas estão mudando no mundo econômico, do trabalho e social, mas o que está realmente mudando? Será que sabemos suficientemente bem o que está mudando?". E a partir da discussão das mudanças do trabalho, surgiu a seguinte questão: “o que é o trabalho?".

Éramos um grupo pequeno de pessoas ${ }^{2}$, e tivemos o sentimento de que era preciso construir um acesso mais profundo e mais rigoroso ao mundo do trabalho, ao que era trabalhar, para avaliar exatamente o que estava mesmo se transformando. Porque ao avaliar a transformação em curso, podia-se concluir coisas graves sobre as competências, a cultura do mundo do trabalho, a obsolescência e o adoecimento. Tudo isso ultrapassava o contexto acadêmico, e nos parecia que a cultura universitária não estava pronta, não era adequada para responder a essa questão. Para avaliar o que está mudando, temos que nos aproximar do trabalho de uma maneira mais simples, diferente da forma como o mundo acadêmico costuma se aproximar.

\section{Revista}

Que referenciais teórico-metodológicos influenciaram na constituição dessa perspectiva?

\section{Yves Schwartz}

Na época, início dos anos 80, toda essa experimentação começou por um estágio - que se chama, na França, 'formação contínua'3 , com trabalhadores da própria região de Provence-
Côte d'Azur, uma microscópica experiência de trabalhar com eles sobre seu próprio trabalho ${ }^{4}$.

\section{Revista}

Nessa época, os trabalhadores que participaram eram da indústria ou já eram dos serviços?

\section{Yves Schwartz}

Os serviços já eram mais presentes do que a indústria. E essa proporção sempre se manteve. A forte presença das pessoas dos serviços acrescentou informações à evolução da experiência e dos conceitos, mas, nessa época, ainda não falávamos em ergologia. Começamos a utilizar essa expressão em 1995, ou 1997. Acho que há uma continuidade fundamental entre essa microexperiência inicial e o que fazemos agora e também o que se faz aqui no Brasil (nós nunca poderíamos imaginar isso, é incrível) ${ }^{5}$. Tínhamos, então, uma intuição sobre a complexidade da atividade de trabalho, mas era somente uma intuição. Todo o movimento foi no sentido de desenvolver essa intuição, e agora, olhando o passado, as referências teóricas. Porque, ao mesmo tempo, tínhamos a experiência desses estágios de formação, que nos permitia trabalhar as situações de trabalho com os próprios trabalhadores. Isso nos trouxe muitas idéias. Mas é verdade que, para que essa experiência fosse fecunda, tínhamos que levar os elementos teóricos aos trabalhadores. Nessa época, foi sempre um vai-e-vem entre os saberes acadêmicos sobre o trabalho e os saberes 'engajados' pelos trabalhadores no mundo do trabalho.

As referências, de início, foram muitas e, sem dúvida, entre elas, contamos com os aportes fundamentais da ergonomia de língua francesa, na herança de Alain Wisner, do Conservatoire National des Arts et Métiers (CNAM) [Conservatório Nacional de Artes e Ofícios]. Jacques Duraffourg foi o ergonomista que fez a ponte com o laboratório de Wisner no CNAM, em Paris. Duas grandes referências: por um lado, o aporte dessa ergonomia ${ }^{6}$ e o de Odonne ${ }^{7}$ (mais conhecido no Brasil do que na França) nos deram referenciais teóricos e metodológicos essenciais; e por outro, e cada vez mais, referências filosóficas da filosofia da vida, conforme George Canguilhem $^{8}$. O primeiro aporte tem uma longa tradição, já que esses ergonomistas se apropriaram do conceito de 'atividade' que vinha da 
psicologia soviética, em que Vigotski e Leontiev são as referências. Esta [a atividade], por sua vez, vinha de Marx, que também retrabalhou a herança de Hegel e Kant, toda uma tradição envolvendo o conceito de atividade. A ergologia conseguiu juntar a história do conceito de atividade, de um lado, com os ergonomistas e, de outro, com a herança da filosofia da vida de Georges Canguilhem.

\section{Revista}

De que forma, nesta perspectiva ergológica, pode-se compreender os conceitos de trabalho, trabalho concreto, trabalho abstrato?

\section{Yves Schwartz}

Abordamos o conceito de trabalho através do conceito de 'atividade industriosa'. Para resumir, quero dizer que qualquer atividade industriosa envolve sempre algo como um 'debate de normas'. Através dessa noção, podemos registrar uma ampliação da diferença entre o 'trabalho prescrito' e o 'trabalho real', considerando a formulação dos ergonomistas. Ampliamos muito essa noção de trabalho real com a noção de 'normas antecedentes', com base na herança de Canguilhem, a propósito da tendência de cada um sempre renormatizar seu meio de vida e seu meio de trabalho. Comecei a definir atividade industriosa como um debate de normas que ultrapassa o meio de trabalho, mas que se situa dentro do meio de trabalho.

É assim que tratamos do conceito de trabalho, e através dessas normas podemos encontrar as dimensões econômicas, da gestão, da renda, do salário e das normas jurídicas. A partir do trabalho como atividade industriosa, reencontramos todas as diferentes dimensões do trabalho. Diversas ciências têm como ponto de partida o trabalhador assalariado, ficando mais próximas das normas antecedentes - o que é um pouco diferente. Mas temos que reencontrar todas essas normas, porque o trabalho é pleno, independente do fato de ser assalariado, formal ou informal, doméstico ou mercantil. Esse é o ponto de partida.

Em relação ao trabalho abstrato e concreto, essa é uma questão freqüentemente colocada. É uma forte referência ao marxismo. Primeiramente, eu diria que o trabalho concreto não é o trabalho real dos ergonomistas. Entendo que Marx se refere ao valor de uso, ele designa o processo de fabricação de um valor de uso. Trabalho concreto designa trabalho para criar valor de uso. Mas, do ponto de vista da ergonomia, eu diria que, para um mesmo valor de uso, para um mesmo trabalho concreto, podemos encontrar muitas formas de trabalho real, referindo-se a circunstâncias singulares, como, por exemplo, as de fabricação de um prédio. Os ergonomistas sempre situam a atividade em torno da necessidade de gerir as variabilidades de um processo de trabalho. É claro que o mesmo trabalho concreto, que supõe os mesmos objetos de trabalho e as mesmas ferramentas, sofre muitas variabilidades, que criam diferenças entre os trabalhos reais para um mesmo trabalho concreto. Não é exatamente a mesma noção, é parecida.

Segundo ponto: acho que, para Marx, a distinção entre trabalho concreto e trabalho abstrato tem como objetivo chamar a atenção sobre o que para ele é essencial - o trabalho abstrato. Porque o âmago da exploração capitalista é o trabalho abstrato, e é a partir dele, e não do trabalho concreto, que podemos definir os conceitos de mais-valia e de exploração. Por isso, penso que para ele a noção de trabalho concreto não é tão essencial. O tempo social de trabalho é o que permite definir o valor de troca, que ultrapassa toda a experiência de trabalho concreto. Em contrapartida, penso que o movimento operário trata com indiferença os aspectos concretos do trabalho, além de tudo que está em jogo dentro do trabalho real. Quando Marx demonstra sua indiferença em relação a todas as formas de trabalho concreto para se apropriar da noção de trabalho abstrato, há o risco da indiferença do movimento operário para com os problemas do trabalho real. Agora, se Marx foi indiferente às questões do trabalho real, esta é uma questão aberta em sua obra e que eu gostaria muito de discutir.

\section{Revista}

Nesse sentido, o conceito de trabalho concreto se aproximaria mais da compreensão da ergologia sobre a atividade humana?

\section{Yves Schwartz}

Penso que sim, efetivamente sim. Se nos aproximarmos dos problemas do trabalho unicamente a partir do trabalho abstrato, não chegaremos à 
perspectiva da ergologia. Isso tampouco vai nos conduzir à ergonomia da atividade. Por isso, a idéia de pensarmos algo como uma 'dialética do trabalho concreto e do trabalho abstrato' poderia nos conduzir melhor às questões tratadas pela ergologia, mas também pela ergonomia. Mas [esta] me parece uma noção insuficiente. E não sei se para o próprio Marx havia mesmo toda essa dialética que nós exprimimos claramente. Não sei se foi através dessa dialética que ele pensou as mutilações do trabalho e da acumulação primitiva. Não sei exatamente qual é a antropologia de Marx. Bom, isso está em aberto, é uma questão.

\section{Revista}

Poderia comentar o significado da expressão 'dramáticas do uso de si'?

\section{Yves Schwartz}

Aqui podemos retomar, de maneira resumida, a questão dos parceiros com quem trabalhamos. No início, com os exemplos mais ligados à indústria, que vieram dos nossos amigos ergonomistas, o mais evidente era a distância entre trabalho prescrito e trabalho real, que quase se podia demonstrar com gráficos. Nos perguntávamos sobre o que acontecia 'entre' os dois. Porque, como se trata de algo entre o corpo e a alma, entre o consciente e o inconsciente, o biológico e o cultural, essa coisa muito enigmática nos conduziu à necessidade de desenvolver o conceito de atividade.

Quando falei pela primeira vez na expressão 'uso de si', em $1987^{9}$, era para transmitir a idéia de que, mesmo numa situação de maior constrangimento, como no trabalho em linhas de montagem, existe atividade, transgressão, 'renormatização' das normas. Isso nos afasta da idéia de pura execução e nos conduz à idéia de uso de si, porque, mesmo nas linhas de montagem, encontramos uso de si - seja 'por si mesmo', seja 'pelos outros'. Podemos então falar que, no trabalho, o uso de si envolve o 'uso de si pelos outros' e o 'uso de si por si mesmo', e aqui a elaboração ergológica e a elaboração filosófica vão extrapolar, generalizar, para além do trabalho assalariado, do trabalho mercantil. Com a presença mais e mais forte das pessoas do setor de serviços, de saúde, de todos os setores do trabalho social, vimos que estes também são normatizados, que têm antecedentes, só que bastante diferentes. Claro que, num mundo tão dominado por normas, com forte expectativa de resultados, o 'trabalho do uso de si por si mesmo' é cada vez menos visível, dado que é cada vez mais impalpável. Com o encontro dos seres humanos que se dá nos serviços, a idéia do debate de normas referidas a valores que eu chamo 'sem dimensão' - como a saúde, a justiça, a cultura, o bem viver, o bem comum - coloca-se mais e mais intensa. A noção de 'dramáticas do uso de si' surgiu um pouco a partir do encontro com esses trabalhadores, que nos falavam desse debate de normas, do encontro com os jovens em dificuldades, da tentativa de inseri-los no mundo do trabalho, e com todos os pacientes do setor saúde. O encontro com essas pessoas acrescentou a idéia de que esse uso de si é sempre uma arbitragem a ser feita, passando sempre pelo uso de si pelos outros, tornando-se uma variável comum, em especial no trabalho. E acrescentaria: dramáticas do uso de si e também 'uso do corpo-si', porque o corpo nos pareceu bastante solicitado, inclusive no trabalho de saúde. Sim, porque, neste caso, podíamos encontrar uma espécie de ruptura com o que sabemos existir no trabalho industrial, quanto ao uso do corpo no uso de si. Com essa idéia, socialmente difundida, de que no setor de serviços o trabalho torna-se mais ou menos imaterial, intelectual, corre-se o risco de não conseguir entender nada do trabalho de saúde, pois é impossível entendê-lo, por exemplo, sem entender o uso de si e o uso do corpo-si.

\section{Revista}

Apesar de reconhecer a importância científica, cultural, social e política do conceito de 'comunidade científica ampliada', criado por Oddone e seus companheiros italianos, entendemos que a proposição do 'dispositivo de três pólos' 10 foi criada a partir de uma avaliação sobre os possíveis limites daquele conceito. Em que sentido o dispositivo de três pólos supera esse conceito? Como ele articula a relação entre os pólos? Como são confrontados os saberes práticos e científicos?

\section{Yves Schwartz}

Não sei se é uma questão de superação. Porque a idéia de comunidade científica ampliada foi 
para nós uma idéia fantástica. Com o livro ${ }^{11}$ de Oddone e de seus companheiros italianos Alessandra Re e Gianni Brianti, Redécouvrir l'expérience ouvrière, estávamos começando a imaginar um dispositivo novo para nos aproximar do trabalhador de uma maneira diferente. Estávamos tentando imaginar, mas sem modelo, e a leitura desse livro foi fantástica. Fantástica porque nos parecia exatamente o que estávamos pensando em fazer. Durante este tempo, conheci Ivar Oddone. Aliás, no ano passado [2004], nós o convidamos para um evento na universidade, Tâches du Présent [Tarefas do Presente], sobre os médicos, em que também estavam presentes sua companheira Alessandra Re e os brasileiros Jussara Brito e Milton Athayde. Para nós, esse reencontro com Oddone foi uma grande emoção. Por isso, não sei se é uma questão de superação, porque o que ele fez nessa época foi algo fantástico.

O que tratamos de fazer com esse modelo? Exploramos duas dimensões um pouco diferentes. A primeira, considerando que sua experiência era bem singular, foi o proveito tirado desse dispositivo, no interior das 150 horas de trabalho anual conquistadas pelo movimento operário e dedicadas à formação - sob controle dos sindicatos -, para compensar as deficiências da escola daquele país. Quando assinalo que a comunidade cientifica ampliada foi uma experimentação em um contexto histórico singular, me remeto ao fato de que os operários da Fiat italiana (sua base inicial) tinham uma cooperação muito forte com o pessoal dos sindicatos (dentro e fora da Fiat) e da universidade. Considero que Oddone desenvolveu isso a partir de um organismo que denominamos, na França, Bourse du Travail, na cidade de Turim. Enfim, encontravam-se aí diferentes aspectos, mergulhados na história do mundo do trabalho e da luta de classes. A nossa idéia era inserir uma coisa como essa nos centros de aprendizagem, de difusão do saber, na universidade. Tentamos instituir esse novo modo de produzir saberes dentro do contexto acadêmico. É um desafio introduzir essa idéia que Oddone chama comunidade científica ampliada neste tipo de lugar, porque a universidade não funciona assim. $\mathrm{O}$ que tentamos implementar era uma espécie de prolongamento da idéia de Oddone.

A segunda dimensão, a partir dessa idéia de comunidade científica ampliada, é a seguinte: em relação ao termo 'científico', como poderíamos retrabalhar o conceito de ciência? Enfim, como compreender o que chamamos 'dispositivo dinâmico de três pólos', qual é a idéia essencial nele presente? Entendemos que, se algo como atividade existe, isso quer dizer que uma situação de trabalho (em parte, mas não inteiramente singular) é sempre, em parte, 'ressingularizada'. Essa idéia vem da herança dos ergonomistas, de Oddone e de Canguilhem.

Se isso é verdade, como fazer para conhecer as situações de trabalho? Claro que temos que trabalhar juntos os saberes que chamarei 'engajados' e aqueles 'desengajados' de uma situação singular, neste caso os saberes conceituais, gerais, fecundos porque gerais, mas insuficientes. Por que são gerais? Porque, em qualquer situação, a atividade sempre se desenvolve enfrentando a necessidade de gerir a singularidade da dramática do uso de si. Então, temos que fazer circular, fazer esse vai-evem entre a riqueza dos saberes envolvendo as normas antecedentes - que estão na nossa vida, no social e no trabalho - e tudo que será recriado pela atividade, em uma situação sempre, em parte, singular. Mas essa segunda parte não pode ser antecipada. Com nossos conceitos e saberes desengajados, não podemos antecipar nem entender exatamente que jogo de valores pesa sobre as dramáticas do uso de si, sempre singulares. Ora, os saberes trabalhados através dessas dramáticas do uso de si são, ao contrário, engajados na história concreta do meu trabalho, dos encontros que fazemos entre homens e mulheres e o meio de trabalho técnico e organizacional, que tem sempre uma singularidade. Claro que a questão científica ou epistemológica é que há, por um lado, homogeneidade entre estes dois saberes, dado que são todos eles saberes, e por outro, há diferenças entre os saberes desengajados que ensinamos (nós, professores) e os saberes engajados que se enraízam, que se ancoram, inclusive, no que chamamos 'corpo-si'. Temos aqui uma complexidade científica e epistemológica, e por tudo isso é que nos confrontamos com o conceito de comunidade científica ampliada. Havia necessidade de melhor trabalhar esse conceito de saber, envolvendo a homogeneidade e a diferença. Parecia-me que essa questão estava aberta em Oddone e que tínhamos a obrigação de desenvolvê-la. 


\section{Revista}

Em um local de trabalho, na prática, seria possível pensar em mecanismos ou dispositivos práticos de gestão que 'resgatassem' o sentido do trabalho? Ou seja, na experiência acumulada por seu grupo em tantos locais de trabalho, quais dispositivos de gestão ou modos de gerir o trabalho prescrito poderiam propiciar um espaço maior ao indivíduo? Em certo sentido, seria o caso de se discutir a possibilidade de que as dramáticas do uso de si e do uso de si pelo outro fossem menos tensas?

\section{Yves Schwartz}

Caso estejamos convencidos de que sempre existe, para todo mundo, a dramática do uso de si, convencidos de que não podemos trabalhar individual e coletivamente sem um debate de normas, isso deve implicar outro olhar sobre a maneira de gerir o trabalho. Além disso, cada situação tem suas características.

\section{Revista}

Mas só isso já parece um desafio. Porque, muitas vezes, temos a sensação de que as pessoas não querem considerar isso. Parece mesmo que alguns trabalhadores talvez queiram ser só 'recursos humanos'. É difícil que os espaços organizacionais discutam ou considerem essas dramáticas.

\section{Yves Schwartz}

Claro que é um desafio. Porque as organizações do nosso mundo assumem inteiramente os valores de mercado, funcionam com autoritarismo, com uma idéia de hierarquia e de imposição de normas um pouco coerentes com a idéia de normatizar previamente o máximo possível, o que é coerente com o poder, com os poderes. O fato de deixar de (re)pensar e (re)trabalhar as formas de organização do trabalho leva à idéia de que temos que normatizar ao máximo. É claro que precisamos de normas antecedentes, porque elas também são patrimônio universal. Se pensarmos, por exemplo, nas normas científicas e técnicas, tudo isso se mistura. De modo que temos que trabalhar juntos, temos que propor normas antecedentes e compartilhar esse conceito de atividade. É preciso normatizar, claro, mas temos que conseguir formas de organização ou de normatização que deixem sempre um espaço para retrabalhar as normas, em função das renormatizações sempre presentes.

\section{Revista}

E até para a conquista da saúde, não?

\section{Yves Schwartz}

É claro. Por exemplo, a questão da saúde pode parecer um pouco menos ligada à escala de valores do lucro, é verdade. Mas as normas, o ritmo de produção, os objetivos a serem cumpridos para a rentabilidade do investimento estão muito ligados à questão do lucro. Qual seria a conseqüência dessa idéia de atividade considerando-se a questão da prevenção, da saúde? Trata-se de saber se o trabalho real implica a execução estrita das normas antecedentes ou se, de fato, o trabalho real é uma espécie de negociação entre as normas antecedentes e a tendência à renormatização, em função do fato de as pessoas serem singulares, em relação ao coletivo. O trabalho real, na verdade, é o resultado das renormatizações, não da estrita aplicação e execução das normas. Ou melhor, é a 'execução' das normas através das renormatizações. Daí concluirmos que os riscos para a saúde não podem ser antecipados somente a partir da análise das normas antecedentes, mas a partir do que se faz efetivamente com todas as normas sociais que pesam sobre o trabalho. Por exemplo, se existe amianto no ambiente de trabalho, isto já pode ser antecipado sem a participação dos trabalhadores. Sabemos o suficiente sobre isso, é algo que já faz parte do nosso patrimônio, um tipo de risco profissional que pode ser antecipado antes mesmo de qualquer atividade de trabalho. Mas existem riscos à saúde que são efeitos das formas de organização do trabalho. É o caso do trabalho de teleatendimento. É um trabalho sempre muito difícil, 'retaylorizado', com muitas prescrições, com riscos para a saúde que resultam das escolhas feitas pelas pessoas frente às chamadas do tele-atendimento. As pessoas podem escolher entre o que se chama 'driblar' a supervisão, ser atento, adivinhar com jeito quando a supervisão não controla, ocupando o tempo para melhor informar o usuário. Essa é uma escolha pessoal, porque ela pode 'driblar' a supervisão e fazer o que para ela é um trabalho melhor. É uma dramática do uso de si com debate de normas. Mas isso implica 
uma espécie de tensão, que pode significar riscos para a saúde da pessoa. Isto é, um risco que não pode ser antecipado ao trabalho da pessoa. É um risco diretamente ligado à maneira pela qual a pessoa renormatiza o seu trabalho.

\section{Revista}

Isso não é algo puramente individual, é uma construção social. No fundo, estamos procurando compreender melhor o que ocorre 'entre' o trabalhador e seu trabalho. Essa relação, essas escolhas não devem ser entendidas como estritamente individuais, não é?

\section{Yves Schwartz}

Isso aponta para o que eu chamo de 'entidade coletiva relativamente pertinente', e é com ela que se cria, que se pode criar. Mas isso não pode ser antecipado. Pode-se criar, mas sempre há uma história. Pode-se criar uma entidade como essa de que falei, no caso do teleatendimento, e favorecer a idéia de não driblar o usuário, mas isto pode não acontecer. Sempre existe uma história parcialmente singular. Por exemplo, podemos tentar discutir a questão da organização da prevenção. Porque, nesse exemplo do trabalho de teleatendimento, era uma questão de LER/DORT [lesão por esforços repetitivos/distúrbios osteomusculares relacionados ao trabalho], algo que custa muito a todos e que também pode custar diretamente à empresa, e depende da execução das leis. Pode-se discutir com os dirigentes: "se eles quiserem diminuir os acidentes, os transtornos, então terão que ficar atentos ao que chamamos de renormatizações das regras impostas. Se quiserem ser eficazes do ponto de vista da prevenção de saúde, serão obrigados a olhar a atividade real, que sempre implicará em renormatizações". É uma escolha a fazer. Claro que os responsáveis oficiais pela organização, os dirigentes, não querem fazer essa escolha, porque ela tem conseqüências sobre a normalidade das coisas. Trata-se da obrigação de reconhecer que as normas não são suficientes para se fazer um trabalho coletivo. Claro que isso conduz a outra maneira de gerir o trabalho. É uma escolha do dirigente aceitar ou não a necessidade de olhar a atividade para diminuir os gastos com as LER/DORT, dado que é um desafio com relação à maneira de impor a autoridade ao trabalhador. Mas suas formas de antecipar as doenças revelam-se, neste caso, completamente insuficientes.

\section{Revista}

No entanto, em algumas situações, poderíamos pensar o renormatizar como algo que contraria a forma como os próprios trabalhadores interpretam o seu trabalho e as normas antecedentes? No exemplo anterior, a busca por eficiência, por um atendimento mais rápido e barato pode levar ao adoecimento do profissional. Pensando, por exemplo, nas normas de segurança do trabalho, concebidas, em princípio, para assegurar a saúde. Para muitos trabalhadores, essas normas de proteção são contrárias ao modo como eles tradicionalmente organizam e interpretam a sua atividade de trabalho. Elas não são valorizadas como proteção ao trabalhador, mas como algo que interfere em sua liberdade. Além de tudo, alguns dispositivos, particularmente os equipamentos de proteção individual, embora possam trazer segurança, são desconfortáveis, fragilizando a própria segurança pretendida. Há uma forte tensão neste ponto. Neste caso, como podemos renegociar a gestão do trabalho?

\section{Yves Schwartz}

Sim, instituir a proteção de uma maneira inteiramente objetiva - sem considerar como se pode desenvolver o trabalho com um certo conforto, sem que seja mais um constrangimento - é uma forma de ignorar o que é a atividade humana. Ontem, em Belo Horizonte a mesma questão foi colocada. É uma questão que teria que ser negociada. Ela deveria ser desenvolvida ou trabalhada no campo da engenharia de produção. Os engenheiros nunca deveriam conceber um sistema, uma maneira de trabalho, de proteção do trabalho, sem interrogar os trabalhadores, as pessoas que irão usar o sistema. Porque a atividade nunca será a pura execução de quaisquer normas. Claro que precisamos de um engenheiro que conheça o funcionamento do sistema, que possa antecipar os riscos. Mas o trabalho não é isso. Não se pode concluir a partir disso. É por isso que há uma luta dentro da empresa, mas também dentro das instituições de saber. E não se tem considerado suficientemente esse ponto, pois, para falar em prevenção, ensino, gerenciamen- 
to, competência, sempre temos que retomar as coisas a partir da atividade, envolvendo o debate de normas.

\section{Revista}

Mas isso não envolveria uma rediscussão do projeto tecnológico? Porque a tecnologia traz uma carga normativa e de valores que pode, de algum modo, comprometer a negociação local. Pensar a atividade não implicaria lidar com uma tecnologia situada?

\section{Yves Schwartz}

Sim, mas por quê? Porque a tecnologia utiliza as leis científicas e as leis da natureza, e cria uma espécie de agregação entre a ambição de toda pessoa que quer impor a sua autoridade para governar o trabalho e apresentar as suas normas como leis, como leis da natureza, como algo que não pode ser discutido. Ora, você não vai discutir a lei da gravidade dos corpos. É uma lei da natureza que não pode ser transgredida. Claro que os sistemas técnicos misturam de maneira complexa o uso de leis da natureza e de leis científicas e implicam maneira de fazer funcionar esse sistema, uma maneira de antecipar a organização do trabalho. Mas não podemos identificar tudo como leis da natureza, o que é diferente. Claro que, com a força das leis científicas, as tecnologias exercem essa fascinação, e se impõem por causa disso. Temos que ajudar os engenheiros a compreender que a engenharia tem uma racionalidade puramente técnica, mas que, em cada situação de trabalho, essa racionalidade não basta; para implementar o sistema concebido, é preciso considerar sempre as racionalidades da atividade.

\section{Revista}

Mas essa questão é muito específica, assim como a análise ergonômica. Nós fazemos uma análise ergonômica em uma determinada empresa, mas não podemos generalizar os resultados para todas as empresas, porque precisamos considerar sempre a particularidade de cada uma. Vamos supor que um engenheiro esteja construindo uma tecnologia considerando o saber dos trabalhadores para desenvolvê-la. Ela vai funcionar para essa organização. Caso se pense nos trabalhadores como o centro das organiza- ções, seria possível aplicar essa tecnologia em todos os lugares?

\section{Yves Schwartz}

Desde que existe a atividade humana, sempre houve uma dimensão de ressingularização e história. Temos que conceber toda criação social, técnica, econômica, política levando em conta o fato de que sempre teremos que reaprender a singularidade relativa do funcionamento concreto dessa criação com o dispositivo de três pólos. Teremos sempre o que eu chamo de 'dupla antecipação', em que os engenheiros podem antecipar a concepção de uma fábrica, por exemplo. A primeira antecipação é o projeto de construção, é fazer a arquitetura, uma atividade muito complexa do seu campo de saber, e cooperar com mecânicos e com todos os envolvidos. Mas claro que ocorrerão algumas renormatizações dos técnicos, dos operários, de todos num lugar, para assegurar que esse projeto seja implantado. Por isso, uma boa concepção da técnica da ergonomia, do gerenciamento, seria sempre recuperar todas essas renormatizações para reinjetá-las nos saberes dos engenheiros. Como os operários têm que aprender o funcionamento normal, os perigos do sistema, eles têm que aprender como a atividade coletiva renormatiza o funcionamento e conhecer as transferências de tecnologia. Qualquer aplicação técnica é sempre uma maneira de transferência de tecnologia, de recriação. Sempre há uma parte, mesmo que mínima, de recriação. Creio que estudar as relações sociais é um desafio constante, não se pode parar. Porque a história é sempre contínua, e cada normatização cria história, cria um evento novo, mesmo que ínfimo.

\section{Revista}

Compreendendo a atividade de trabalho como gestão, podemos considerar que os trabalhadores portariam a potência de gerir, de criar sobre o trabalho empregando neste movimento o uso de si. Este não compreenderia também a autogestão? Ou microprocessos autogestionários? Em caso afirmativo, os trabalhadores não estariam sob o constante dilema de se movimentar na autogestão ao mesmo tempo em que estamos todos mergulhados em processos de heterogestão? De que forma isto repercutiria na saúde? 


\section{Yves Schwartz}

Essa formulação é muito pertinente. O que vocês chamam de 'grupos de autogestão' eu prefiro chamar de 'entidades coletivas relativamente pertinentes'. Claro que não podemos nos desenvolver de uma maneira confortável se o mundo social faz exatamente o contrário. Por isso, a questão do que chamo 'ergo-engajamento' situa-se tanto no nível mais singular, no ínfimo das coisas, quanto no nível mais global. Claro que, assim sendo, essa questão é tão macropolítica quanto microscópica. Impossível ser auto- gestionário enquanto todos os que o cercam pautam-se pela concorrência, pela competitividade entre seres humanos - há uma contradição. Não tentamos dar uma solução. A ergologia não tem mesmo nenhuma solução a oferecer. Sinalizamos um esforço para mudar um pouco o olhar sobre todas essas questões e dar visibilidade às dramáticas do uso de si, o que exige invenção, recriação permanente. Não se pode dar solução - nem política, nem econômica -, mas sabemos que, na ausência desse tipo de olhar, haverá crises, doenças, infinitas doenças.

\section{Notas}

${ }^{1}$ Convidamos para a realização da entrevista as pesquisadoras Luciana Gomes e Ana Lúcia Abrahão (Laboratório de Educação Profissional em Gestão em Saúde), e Mônica Vieira (Laboratório de Trabalho e Educação Profissional em Saúde) da Escola Politécnica de Saúde Joaquim Venâncio (Fundação Oswaldo Cruz). Agradecemos aos pesquisadores Jussara Brito (ENSP) e Milton Athayde (UERJ) pela discussão prévia do roteiro de entrevistas e revisão final do texto.

2 Os três professores do departamento diretamente envolvidos eram, além de Schwartz, o lingüista Daniel Faïta e o sociólogo Bernard Vuillon. De fora, destaca-se o ergonomista Jaques Duraffourg.

${ }^{3}$ Estágio então denominado "Cultura profissional, saber-fazer, mutações tecnológicas".

${ }^{4}$ Ver Y. Schwartz e D. Faïta (orgs.). L'homme producteur: autour des mutations du travail et des savoirs. Méssidor/ Sociales, 1985.

${ }^{5}$ Referencia as inúmeras colaborações com grupos de pesquisa no Brasil.

6 Ver em português: F. Guérin, A. Laville, J. Duraffourg \& A. Kerguelen. Compreender o trabalho para transformá-lo. São Paulo, Edgard Blücher, 2001.

${ }^{7}$ Ivar Odonne, médico e psicólogo do trabalho, uma das principais referências do chamado 'movimento operário italiano de luta pela saúde' (MOI).

${ }^{8}$ No que tange ao trabalho, ver Canguilhem. Meio e normas do homem no trabalho. Pro-posições, v. $12, \mathrm{n}$.

${ }^{9}$ Ver em português: Trabalho e uso de si. Pro-posições, n. 32, 2000

10 Ver em português: Ergonomia, filosofia e exterritorialidade. In: F. Daniellou (org.). A ergonomia em busca de seus princípios: debates epistemológicos. São Paulo, Edgard Blücher, 2004, p. 141-180; Y. Schwartz e L. Durrive (orgs.). Trabalho e ergologia: conversas sobre o trabalho. Rio de Janeiro, DP\&A, no prelo.

11 Oddone, Ivar; Re Alessandra e Brianti, Gianni. 1981. Redécouvrir l'expérience ouvrière: vers une autre psychologie du travail? Paris: Sociales. 
